are ill and die outside its boundaries, it is no less true that a great many others come to the city sick and die there. This matter has been gone over very carefully, and the conclusions arrived at are that the deaths of this kind taking place in and out of the city pretty well balance each other. After all, however, the number of such cases is so small that it could hardly be expected to affect the percentage. As to the admirable work done by the Chicago Board of Health by means of its weekly bulletin-which is a model publication of its kind-I may say that we have under consideration the adoption of some similar plan for the weekly discussion of sanitary problems. Before closing I would like to say a word as to the excellent work which has been done by Dr. Knopf, and the enormous influence his writings have had in extending a knowledge of tuberculosis and the means to be taken for its prevention and cure.

\section{A PECULIAR CASE OF RECURRENT BULLOUS ERUPTION.*}

WILLIAM S. GOTTHEIL, M.D.

Physician to the City Hospital, Lebanon and Beth-Israel Hospitals. NEW YORK.

It may well be that the case which I shall briefly describe is of a type not unusual in some localities, or that it is not infrequently seen by those who practice in pediatrics. But I have never come across one precisely similar, and its characteristics, both positive and negative, are such that I am unable to classify it under the heading of any of the ordinary dermatoses. These considerations embolden me to place on record the following case :

Mamie K., $5 \frac{1}{2}$ years old, was brought to my clinic at Lebanon Hospital, with the following history: Since her second year there has appeared each autumn a skin eruption similar to the one that is now present; during the spring and summer there is absolutely nothing the matter with her integument. Each attack began with the appearance of a. few watery blisters, which increased up to a certain size, and then either ruptured or dried up. From time to time new ones appeared, thus prolonging the course of the disease to several weeks or months. Then, quite spontaneously, the blisters ceased to form and the child was well. Subjective sensations were entirely absent, so that the child had had no treatment at all; and the sole reason that she was now brought to the clinic was the fact that the accident of location of some lesions in this attack does give her trouble. The first attack occurred in her second year; there were only two or three small bullæ on the backs of the hands, and the eruption lasted but a short time. The second attack in her third year was a little worse; there were more blisters, their size was larger, and the eruption lasted longer. In the attack of the fourth year the forearm and legs were affected, as well as the hands, and the severity of the symptoms was increased. The present fourth attack is the worst that she has ever had. It has been present since September (over three months); the blisters are larger than they have ever been; some have appeared on the mons veneris and abdomen, and there have been a number of lesions on the buttocks, thighs, legs and arms. Each one takes two or three weeks to run its course, instead of a week, as did the early ones; and new efflorescences are continually coming out, so that since this attack began, there have always been some score or two of lesions present in various stages at least. Within the last few days some large blisters had appeared on the ankles and soles; and the child had been unable to walk on account of the pain that they occasioned.

There had been neither itching nor pain before or after the appearance of any of the lesions. Most of them were accidentally discovered when the child was being dressed or bathed. When rupture of the bullæ had occurred, the skin beneath the detached epidermis was found moderately reddened, but not especially sensitive; the mother usually applied a bandage to

* Read at the Fifty-third Annual Meeting of the American Medical Association, in the Section on Cutaneous Medicine and Surgery, aud approved for publication by the Executive Committee : Drs. W. T. Corlett, L. Duncan Bulkley and W. L. Baum. the part for a day or two. There has never been any apparent relationship to pressure or other injury; the blisters have not been commoner around the ankles or waist or on the knees or elbows, than elsewhere; they have never come on after a fall or a bruise. There are no other children in the family, and the mother can give no history of any relative on either side of the family having been similarly affected.

Examination showed the child to be perfectly healthy as regards her internal organs. She is a fairly robust girl of the blond Germanic type, and is physically and mentally normal. The lesions present were almost all on the lower limbs; there are some 50 of them from the hips down. The great majority of these, however, were only the dried remains of smaller blebs, or the fading marks of older ones. There were large bullæ, however, just below the right internal malleolus, on the inner edge of the sole of the left foot, and on the upper thighs. These were the new ones that had appeared during the last few days. On the mons veneris, lower abdomen, and arms only the stains of vanished lesions were apparent.

In the weeks following this first examination, I had abundant opportunity to watch the development of the bullæ from their beginning. Without any local prodromal symptoms, either subjective in the shape of itching, formication or pain, or objective as redness, elevation or whealing, there would appear a minute vesicle, tense, globular, and filled with a trans-

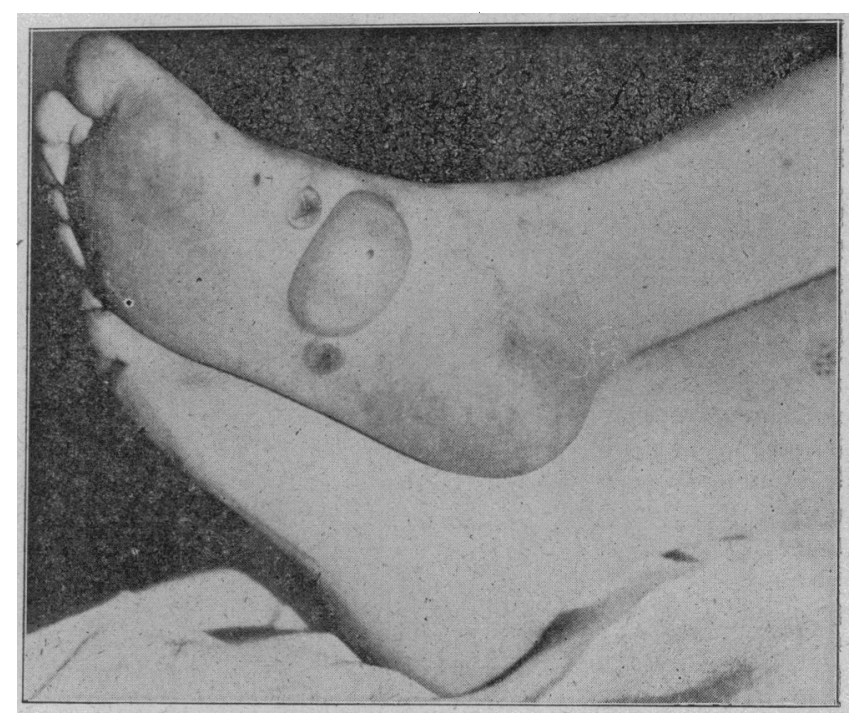

parent yellow serum. This would rapidly increase in size, becoming as large as a bean in 24 hours, and walnut-sized or over in from two to three days if it was not accidentally rup. tured. In the case of the bulla of the sole I took care to prevent this happening; and it grew to be as large as a goose-egg, and stretched across the sole. I was then compelled to rupture it on account of the disability that it occasioned the patient. After rupture of the largest bullæ the epidermis could be removed at once, since epithelial repair had largely taken place under it, and the surface was not sensitive.

All attempts on my part to produce bullæ by friction, pinching, etc., were fruitless, thus confirming the mother's statement as to the spontaneous origin of the lesions.

Knowing from the previous attacks that the disease was selflimited, I did not deem it necessary to institute any very vigorous treatment, and put her on moderate doses of arsenic. In January the lesions began to become less frequent, and late in February they ceased to appear. During this period I made it a practice to rupture the bullæ early, and none of them attained any very large size.

Here, then, was a recurrent bullous eruption in a child, coming on in the fall of four successive years, running a definite course, and unaccompanied by the other symptoms usually met in lesions of this nature. It was certainly not an epidermolysis bullosa, for there was no hereditary history, no relationship to injury, and the disease ran a definite course. It was not a 
bullous urticaria, for there was no itching, and there never were any other urticarial lesions on the child's body; and a similar argument holds for a bullous erythema. Dermatitis herpetiformis is grouped and inflammatory; this eruption had neither of these characteristics. In a female adult an artificial (cantharidal) eruption might be thought of, but it is not possible that a child of such tender years would produce them, and I am very sure that her mother did not do so. I should hesitate to call it a benign pemphigus, on account of its periodicity and the absence of. an inflammatory areola around the bullæ. Yet this latter designation is apparently the one that would fit it best. and is the one that I should select, if compelled to make a choice.

\section{DISCUSSION.}

Dr. L. WeIss, New York-I would like to ask Dr. Gottheil what treatment he has pursued. I saw, in consultation, a similar case of a woman aged about 50, feverish and in a low condition. She had two blebs, one on the outside of the left malleolus of the size of a hen's egg, and a smaller one on the right wrist. I recommended simply a zinc-gelatin varnish, and in a few days under this occlusive application the denuded surface cleared itself, and within ten days the suppurative symptoms subsided, and the integument was replaced.

Dr. JAY F. Scinamberg, Philadelphia-I should like to report a remarkable case which this paper calls to my mind. I saw a few weeks ago a colored man, aged 21 , who exhibited on the palms of the hands and on the fingers numerous blebs varying L. diameter from 1 to $2 \mathrm{~cm}$. Lesions of a similar character were present on the lips, tongue and buccal mucous membrane. In the beginning of the attack the patient was obliged to subsist on liquid food owing to difficulty in swallowing. The patient had experienced three distinct attacks of this same character at intervals of six months and a year; in all of these the same regions were involved. The patient had had syphilis. There are many bullous eruptions which are most obscure in their nature and extremely difficult to classify. Many of these are being thrust into the class of dermatitis herpetiformis, thus extending the limits of this disease beyond the boundaries established by Dühring.

Dr. M. L. Herdivesfei.d, Cineinnati--Cases of bullous eruptions are always a matter of peculiar interest by virtue of their obscure nature, and in discussing this paper I wish to briefly mention a ease, not only because it is of particular interest to me, but also to determine whether or not any of my fellow mem. bers have had a similar experience. A case which has been recently reported to the Cincinnati Lancet-Clinic (Aug. 2, 1902) under the name of "Epidermolysis Bullosa (Faclitia)" or traumatic $x$-ray bullous dermatitis, was exposed to the rays during three sittings of five minutes each, and was followed by slight erythema and a marked tendency to bullous formation over areas subjected to slight trauma. To all intents and purposes this case could be called an artificially-induced case of epidermolysis bullosa, through heredity, its beginning in early infancy and other features were lacking, as in some of the recorded cases of traumatic bullous eruption. The blood showed no variation from the normal, and incidentally I would like to ask Dr. Gottheil if the blood examination, or the contents of the bullæ in his case, showed any interesting changes.

Dr. David Lieberthai, Chicago-I have seen a case similar to that of the essayist, through the courtesy of Dr. I. A. Abt. Soon after birth the child exhibited bullæ in the mouth and on the lower extremities. These bullæ had a thin roof and clear contents and soon broke down, healing taking place in a few days. The presence of scars near the ankles was strongly suggestive of syphilis, but no other symptoms were present supporting this supposition. At intervals of months new blebs appeared on the lower as well as the upper extremities, pursuing the same course, although the mouth remained free. The number of blebs at each eruption was limited to from one to three. This case, too, is difficult of classification and further observation might lead to its proper interpretation.
Dr. GotTherL-I presented this case. as an example of a elinical type with which I was not familiar. In response to the first question I would say that it was undoubtedly selflimited; each of the previous attacks ended spontaneously, without any treatment at all; and the one that 1 observed had practically no treatment either. I have not seen anything similar from exposure to the Roentgen rays, but I know that such have been recorded. The bullous eruption from $x$-ray exposure, however, comes on very slowly, lasts a long time, and leads to very intractable ulceration; here the individual bullæ lasted but a very few days, were superficial, healed spontancously without destruction of tissue, and the malady was prolonged by the appearance of new bullæ on other parts. Besides this, there had never been any exposure to the rays.

The diagnosis apparently lies between a benign pemphigus and a bullous erythema, with some very cogenc arguments, however, against the adoption of either designation. It is for this reason that I have regarded the case as worthy of record.

Havana Leper Hospital.-At the meeting of the Orieans Parish Medical Society, Oct. 11, 1902, Dr. Isadore Dyer gave an interesting account of his visit to the Havana Leper Hospital. Although founded in 1681, the Hospital San Lazzaro assumed importance only in 1861, when the present imposing building was erected. This occupies a prominent position on one of the main thoroughfares only a few hundred yards removed from the bay front and opening on a broad plaza. The entrance from the street discloses a large chapel for the use of the public, to which the patients in the hospital have access in a reserved space just off the chancel, separated on each side by high iron railings, one side for females, the other for males. There are in all 114 patients, mostly native, and about equally divided between male and female; only a few children, the youngest about eight years, and only a few negroes. Quarters for the two sexes are separateiy arranged and a distinct infirmary is provided for those lepers who become ill o: some concurrent malady. Seven sisters of charity are in charge of the nursing and domestic departments, and help is received, not required, from those patients who are able to render it. The whole establishment is cleanly and strict attention is given to ventilation and hygiene. As in all Cuban establishments, the bathing facilities are meager. Treatment at this institution seems to present about the same results as is common elsewhere. Most reliance is placed by Dr. Alfonso, the head of the hospital, on Chaulmoogra oil, and he believes his best results are obtained with this remedy. Experimental work has been done for the past eight months with red mango bark, but as yet without result. Baths of benzoinated water, sulphurated water, etc., are employed in some cases. Carasquilla serum has been used and abandoned. Arsenic and bichlorid of mercury are among the other remedies ehiefly employed. The salicylates and ichthyol are also used. Strychnin as a regular treatment did not seem to appeal to Dr. Alfonso as it has to Dr. Dyer, for the latter has always held strychnin as a sheet anchor in leprosy, and has never treated a case without maintaining this drug throughout, no matter what else he may have used. Dr. Dyer was struck, in the short time at his disposal to observe these patients, with the large number of pure tropic types, the sort of cases found in Brittany and in Constantinople, those cases which have led to the separation of Morvan's disease as an entity. Of all the cases shown him at the San Lazzaro Hospital, there were few of the tubercular type, the type in which the bacilli arè found freely colonized. The fact that so many of the cases were natives and that they presented for so large a part the evidences of what ZambacoPacha has called "effetex" leprosy, possibly explains the fact that there is no instance recorded of contagion having occurred among the attendants of this institution. Altogether the appearance and detail of the Havana Leper Hospital, and it is not an asylum, impressed the doctor with the highest sense of respect for a well-organized and managed institution. 